\title{
Application of amplified fragment length polymor- phisms markers to study the hybridization between Pinus sibirica and P. pumila
}

\author{
G. Vasilyeva, V. Semerikov
}

\begin{abstract}
Vasilyeva G., Semerikov V., 2014. Application of AFLP markers to study the hybridization between Pinus sibirica and P. pumila. Ann. For. Res. 57(2): 175-180, 2014.
\end{abstract}

Abstract. The genetic diversity of Pinus sibirica, P. pumila, and their hybrids, in a mixed natural stand was studied using amplified fragment length polymorphisms (AFLP). The stand was situated in the northern slope of the Khamar-Daban Ridge. Hybrid trees were determined by their morphological traits in the field. Three AFLP primer combinations detected 167 bands in 35 putative hybrids, and in 25 P. sibirica and 26 P. pumila individuals. Genetic variation in the hybrids was the highest, and was the lowest in $P$. sibirica. Principal coordinate analysis clustered $P$. sibirica, $P$. pumila and the hybrid genotypes into three distinct groups. Nei's distance between the species was 0.193 , whereas that between the hybrids and $P$. sibirica was 0.047 , and between hybrids and $P$. pumila it was 0.074 . Application of AFLP in the future studies promises to increase our knowledge of P. sibirica and $P$. pumila hybridization. Keywords interspecies hybridization, five-needle pines, Pinus sibirica, Pinus pumila, amplified fragment length polymorphisms, AFLP, genetic variation.

Authors. Galina Vasilyeva (galina_biology@mail.ru) - Institute of Monitoring of Climatic and Ecological Systems, Siberian Branch of the Russian Academy of Sciences, 10/3, Academichesky Ave., 634055 Tomsk, Russia; Vladimir Semerikov - Institute of Plant and Animal Ecology, Ural Branch of the Russian Academy of Sciences, 202, 8 Marta Str., 620144 Ekaterinburg, Russia.

Manuscript received May 28, 2014; revised August 29, 2014; accepted September 05, 2014; online fi rst September 10, 2014.

\section{Introduction}

Siberian stone pine (Pinus sibirica Du Tour) and Siberian dwarf pine (P. pumila (Pall.) Regel) are five-needle pines from the section Quinquefoliae, subgenus Strobus, genus Pinus. Much of the ranges of these species are located in Russia. Natural hybrids between the species occur in the sympatric zone (Goroshkevich 1999, Goroshkevich et al. 2008). L.K. Pozdnyakov (1952) described the first putative hybrid in southern Yakutia. He noted the intermediate size and structure of the needle, and the intermediate size and mass of the seeds of the 
hybrid tree. G.I. Galaziy (1954) found a putative hybrid in the upper reaches of the Langatuy River in the Khamar-Daban Ridge (1650 $\mathrm{m}$ above sea level). Later, V.N. Molozhnikov (1975) described tree-like forms of P. pumila, and assumed they were hybrids because they combined features of both $P$. pumila and $P$. sibirica. In these studies, the hybrids were described on the basis of their morphological traits. Hybridization between $P$. pumila and $P$. sibirica had remained controversial until the study of Politov et al. (1999). They showed that P. sibirica and P. pumila were differentiated by the allozyme locus $S k d h-2$ and that putative hybrid individuals were heterozygous for the parent alleles at this locus (Politov et al. 1999). Since then, all putative hybrids have been identified using allozymes (Petrova et al. 2007, Petrova et al. 2008, Petrova et al. 2012).

Amplified fragment length polymorphisms (AFLPs) (Vos et al. 1995) are an efficient method for investigating genetic variation and are an alternative to other methods commonly used in plant hybridization studies, such as allozymes, microsatellites and inter-simple se- quence repeats. The AFLP method is cheap, provides unlimited numbers of genetic markers and does not require prior information of the target fragment sequence. Disadvantages of the AFLP method include difficulties in joining data arrays produced in separate experiments and the dominant nature of the markers, making it impossible to distinguish between dominant homozygous (1/1) and heterozygous (1/0) genotypes (Bensch \& Åkesson 2005). The aim of this work was to study the genetic variation in a mixed population of $P$. sibirica, $P$. pumila and their hybrids, using AFLP markers.

\section{Materials and methods}

Branches from 25 P. sibirica, 26 P. pumila and 35 hybrid trees were collected in August 2011 from a mixed stand located on the northern slope of the Khamar-Daban Ridge (Fig. 1), which is approximately $24 \mathrm{~km}$ south-west of Lake Baikal near Chertovo Lake $\left(51^{\circ} 29^{\prime} \mathrm{N}\right.$, $103^{\circ} 35^{\prime} \mathrm{E}, 1728 \mathrm{~m}$ above sea level).

Hybrids were identified by their morphologi-

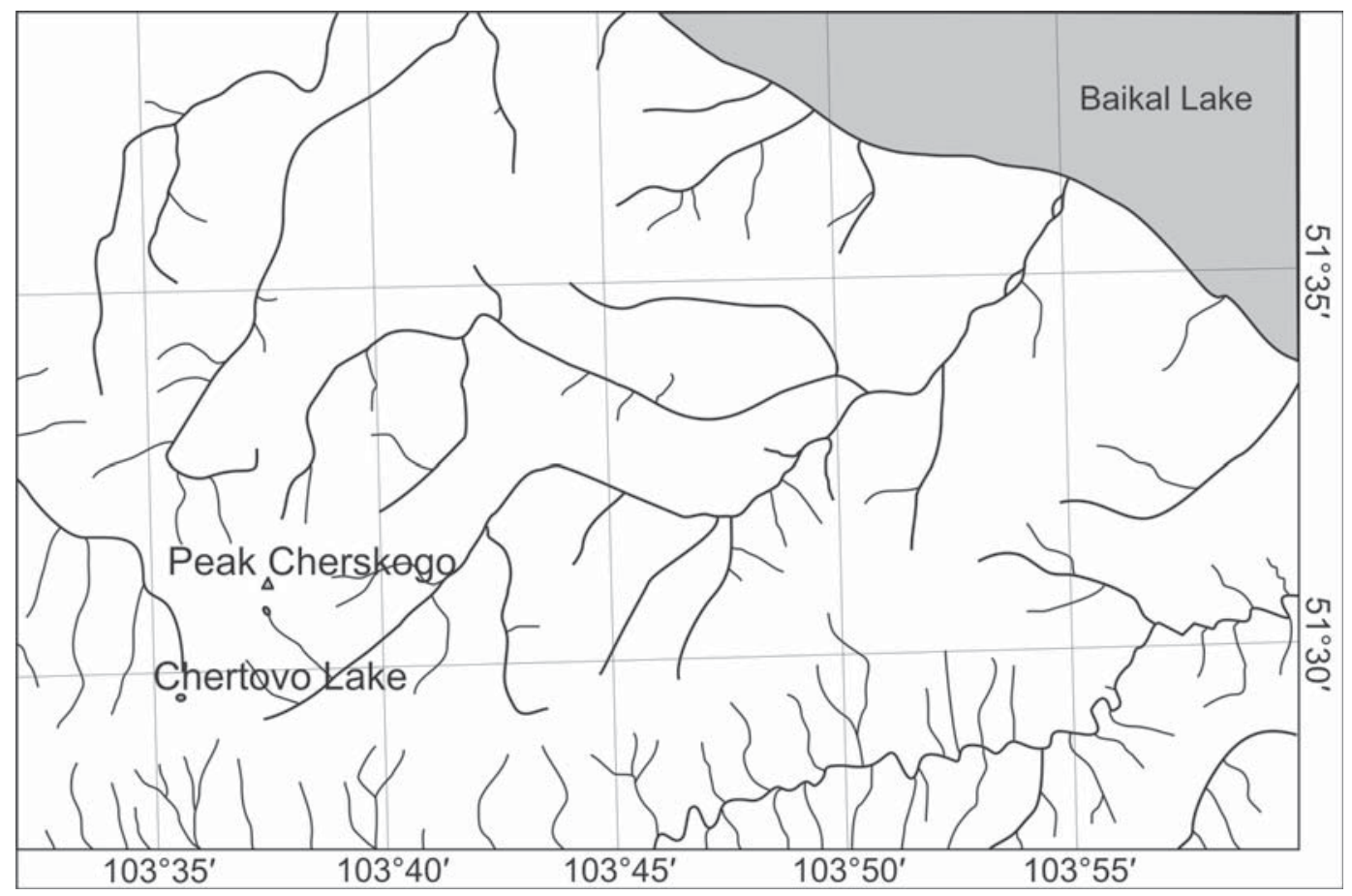

Figure 1 Location of studied mixed population 
cal traits. The first of these traits was tree habit. Hybrids did not have a vertical trunk and the butt was often curved. Some hybrids did not have a pronounced trunk and their crown was formed by several trunk-branches. However, in contrast to $P$. pumila, not all the trunk-branches of the hybrid plant were prostrate. The second important trait was the color of the ripening cones, which were purple in hybrid cones, like those from P. sibirica. Additionally, the hybrid cones were larger than those of $P$. pumila but smaller than those of $P$. sibirica. In the depression near Chertovo Lake, the hybrids trees possessed the intermediate traits compared with parental species, whereas on the slopes, they had acquired a creeping form and could only be distinguished from $P$. pumila by their large, purple cones.

DNA was isolated from $0.1 \mathrm{~g}$ of fresh buds and needles according to the method of Devey et al. (1996) (cited in Ostrowska et al. 1998). The resulting DNA was then purified from RNA by incubation with RNase $(100 \mu \mathrm{g} / \mathrm{ml})$ at $65^{\circ} \mathrm{C}$ for $30 \mathrm{~min}$. The DNA concentration was measured using spectrophotometer (Shimad$\mathrm{zu})$. AFLP genotyping was based on a modified version of the method of Vos et al. (1995) and followed the protocol described by Samils et al. (2001), which uses fluorescently-labeled EcoRI primers. Three primer combinations that resulted in clear amplification profiles were selected for the analysis (EcoRI AGC NED ${ }^{\mathrm{TM}}$ / $M s e I$ CCTG, EcoRI ACG JOI ${ }^{\mathrm{TM}} / M s e \mathrm{I}$ CCTC, EcoRI ACT FAM ${ }^{\mathrm{TM}} / \mathrm{Mse}$ I CCTC). Internal size markers (GeneScan ${ }^{\mathrm{TM}}-500 \mathrm{ROX}^{\mathrm{TM}}$ Size Standard) were used in each sample to size the fragments accurately. After the electrophoresis on a 3130 Genetic Analyzer instrument (Applied Biosystems, Applera Corp., Foster City, CA, USA), raw data were processed with the GeneMapper $^{\circledR}$ software version 4.0 (Applied Biosystems). Only fragments ranging between 50 and $500 \mathrm{bp}$, and peaks with heights above 50 relative fluorescence units (rfu) were scored. All AFLP profiles were checked manually and the corresponding individuals were removed from the analysis in case of bad amplification or presence of too many unique fragments. After visual inspection, only peaks with unambiguous interpretation were used for analysis.

Percentage of polymorphic loci $(P)$, mean number of alleles per locus $\left(N_{\mathrm{a}}\right)$, expected heterozygosity $\left(H_{\mathrm{e}}\right)$ and an unbiased estimate of the expected heterozygosity $\left(U H_{\mathrm{e}}\right.$; Nei 1978) were calculated based on presence/absence of AFLP fragments in the matrix using GENALEX 6.41 (Peakall \& Smouse 2006) for the species and the hybrids. Nei's unbiased genetic distance among the studied species and hybrids was estimated (Nei 1978). Principal coordinates analysis (PCoA) was performed to visualize the genetic relationships among the studied individuals.

\section{Results}

In total, 167 AFLP fragments were obtained from 86 trees of the species and the hybrids. The numbers of bands produced by the primer combinations differed, with 48, 57 and 62 bands scored from EcoAGC/MseCCTG, EcoACG/MseCCTC, EcoACT/MseCCTC, respectively. The hybrids showed the largest genetic variation scores, whereas $P$. sibirica had the lowest (Table). The genetic variation scores for $P$. pumila were similar but smaller those for the hybrids.

AFLP analysis showed that all presumed hybrids were intermediate between parental species and clearly differed from them (Fig. 2). The PCoA coordinate 1 differentiated the three groups (species and hybrids) and coordinate 2 corresponded to variation within the group. The hybrid cluster was positioned between the parental species. Nei's distance between the species was 0.193 , between P. pumila and hybrids was 0.074 , and between P. sibirica and hybrids was 0.047 , which indicated some bias of the hybrids toward the $P$. sibirica parents. 
Table 1 Percentage of polymorphic loci $(P)$, mean number of alleles per locus $\left(N_{f}\right)$, expected heterozygosity $\left(H_{e}\right)$ and an unbiased estimate of the expected heterozygosity $\left(U H_{e}\right)$ of $P$. sibirica, P. pumila and their hybrids estimated by AFLP markers

\begin{tabular}{lccc}
\hline Parameter & P. sibirica & Hybrids & P. pumila \\
\hline$P$ & 58.080 & 83.830 & 80.840 \\
$N_{a}$ & 1.395 & 1.808 & 1.707 \\
$H_{e}$ & 0.178 & 0.265 & 0.261 \\
$U H_{e}$ & 0.182 & 0.269 & 0.266 \\
\hline
\end{tabular}

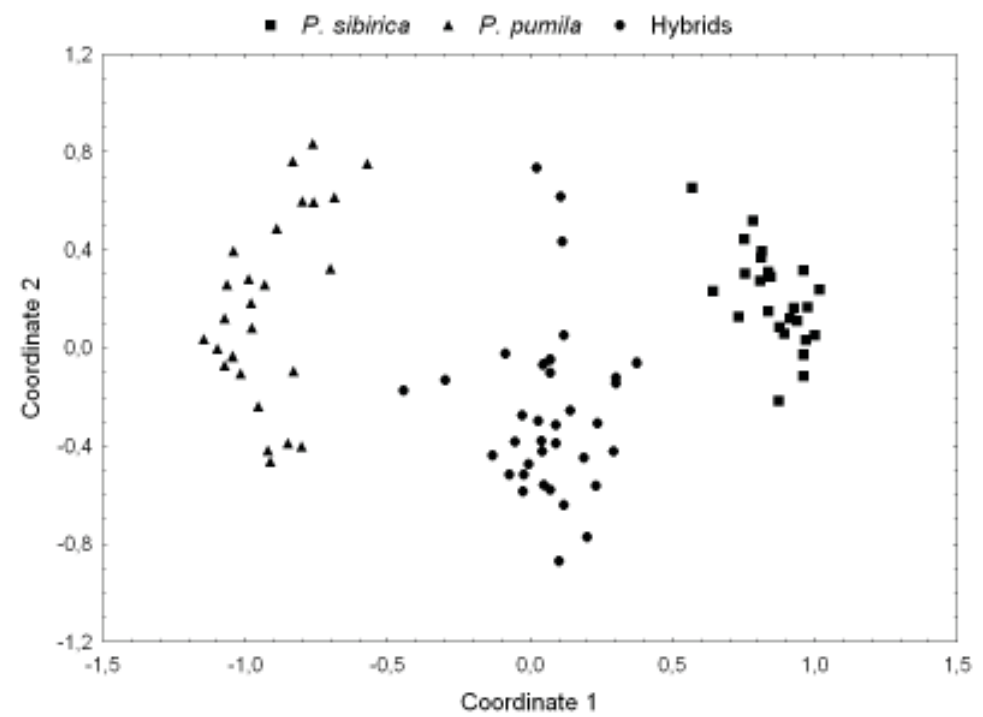

Figure 1 Principal coordinate scatter plot showing the distinct distribution of $P$. sibirica, P. pumila ant their hybrids into different clusters in the two dimensions

\section{Discussion}

Combining two significantly different genomes usually results in hybrids that are more genetically variable than their parental species (Anderson 1953, Stebbins 1959). Natural hybrids of $P$. sibirica and $P$. pumila are no exception. An allozyme survey of genetic diversity in $P$. sibirica, P. pumila and their hybrids (Petrova et al. 2007, 2012) showed that hybrids had the highest variation in all three mixed populations investigated, which corresponded with our results. Moreover, as in our study, the allozyme (Politov and Krutovsky 2004) and inter-simple sequence repeat markers (Liu et al. 2005) data also confirmed that $P$. pumila was more variable than $P$. sibirica.
How to explain an asymmetry in genetic distances between the hybrids and the parent species, which showed a slight bias of the hybrids toward P. sibirica? Perhaps this is normal for hybrids. For example, AFLP analysis of hybrids between Populus ciliata and $P$. maximowiczii showed more asymmetry and considerable shift of hybrids to one of the parental species on PCoA scatter plot (Chauhan et al. 2004). The observed asymmetry is probably associated with differentiated survival of different genotypes. Alternatively, the asymmetry could have occurred because of higher homozygosity of $P$. sibirica and consequently higher probability of offspring containing the band transmitted from $P$. sibirica parent.

Our earlier research suggested that the hy- 
brids display sufficient seed production to form next hybrid generation, and the pollen of the hybrids pollinate the parental species. Consequently, they have a significant effect on the introgression of the species (Goroshkevich et al. 2008, Petrova et al. 2008, Vasilyeva 2011). In the near future, it would be interesting to study other groups of P. sibirica and P. pumila hybrids found in different locations of the sympatric zone. Taking into account the possibility of distinguishing $\mathrm{F}_{1}$ and $\mathrm{F}_{2}$ by means of AFLP markers (Miller 2000), we could further investigate the $P$. sibirica- $P$. pumila hybridization intensity and evolutionary consequences.

\section{Acknowledgements}

This study was supported by the Russian Foundation for Basic Research (Project No. 11-04-90807).

\section{References}

Anderson E., 1953. Introgressive hybridization. Biological Reviews. 28(3): 280-307. DOI: 10.1111/j.1469185X.1953.tb01379.x.

Bensch S., Åkesson M., 2005. Ten years of AFLP in ecology and evolution: why so few animals? Molecular Ecology. 14: 2899-2914. DOI: 10.1111/j.1365294X.2005.02655.x.

Chauhan N., Negi M.S., Sabharwal V., Khurana D.K., Lakshmikumaran M., 2004. Screening interspecifi chybrids of Populus $(P$. ciliate $\times$ maximowiczii) using AFLP markers. Theoretical and Applied Genetics. 108:951-957. DOI: 10.1007/s00122-003-1508-5.

Galaziy G.I., 1954. Timberline fl ora in the mountains of Eastern Siberia and its dynamics. Proceedings of Botanical Institute, USSR Academy of Science 3(9): 210-329 (In Russian).

Goroshkevich S.N., 1999. On the possibility of natural hybridization between Pinus sibirica and Pinus pumila inthe Baikal Region. Botanicheskij Journal 84(9): 48-57 (In Russian).

Goroshkevich S.N., Popov A.G., Vasilieva G.V., 2008. Ecological and morphological studies in the hybrid zone between Pinus sibirica and Pinus pumila. Annals of Forest Research 51: 43-52.

Liu G.-F., Dong J.-X., Jiang Y., Lu Y.-F., Jiang J., Zhao G.Y., 2005. Analysis of genetic relationship in 12 speciesof Section Strobus with ISSR markers. Journal of Forest
Research. 16: 213-215. DOI: 10.1007/BF02856817.

Miller L.M., 2000. Classifying genealogical origins in hybrid populations using dominant markers. Journal ofHeredity. 91: 46-49. DOI: 10.1093/jhered/91.1.46.

Molozhnikov V. N., 1975. Siberian dwarf pine in mountain landscape of Northern Baikal region. Moscow, Nauka. 203 p. (In Russian).

Nei M., 1978. Estimation of average heterozygosity and genetic distance from a small number of individuals. Genetics. 89: 583-590.

Ostrowska E., Muralitharan M., Chandler S., Volker P., Hetherington S., Dunshea F., 1998. Optimizing conditions for DNA isolation from Pinus radiata. In Vitro Cellular and Developmental Biology-Plant. 34: 108111. DOI: $10.1007 / \mathrm{BF} 02822773$.

Peakall R., Smouse P.E., 2006. GENALEX 6: genetic analysis in Excel. Population genetic software for teaching and research. Molecular Ecology Notes. 6: 288-295. DOI: $10.1111 /$ j.1471-8286.2005.01155.x.

Petrova E.A., Goroshkevich S.N., Belokon M.M., Belokon Y.S., Politov D.V., 2008. Population genetic structureand mating system in the hybrid zone between Pinus sibirica Du Tour and P. pumila (Pall.) Regel at the eastern Baikal Lake shore. Annals of Forest Research. 51: 19-30.

Petrova E. A., Goroshkevich S. N., Belokon M. M., Belokon Y. S., Politov D. V., 2012. Natural hybridization Siberian stone pine (Pinus sibirica Du Tour) and Siberian dwarf pine (P. pumila (Pallas) Regel) in southern Zabaikalie. Khvoynyye borealnoy zony. 30(1): 152-156 (In Russian).

Petrova E.A., Goroshkevich S.N., Politov D.V., Belokon M.M., Popov A.G., Vasilyeva G.V., 2007. Seed production and genetic structure of populations in natural hybrid zone of Siberian stone pine and Siberian dwarf pine. Khvoynyye borealnoy zony. 24: 329-335 (In Russian).

Politov D.V., Belokon M.M., Maluchenko O.P., Belokon Y.S., Molozhnikov V.N., Mejnartowicz L.E., Krutovsky K.V., 1999. Genetic evidence of natural hybridization between Pinus sibirica Du Tour and P. pumila (Pall.) Regel. Forest Genetics. 6: 41-48.

Politov D.V., Krutovsky K.V., 2004. Phylogenetics, genogeography and hybridization of fi ve-needle pines in Russia and neighboring countries. In: Breeding and genetic resources of fi ve-needle pines: growth, adaptability, and pest resistance. Proceedings of the IUFRO Five-Needle Pines Working Party Conference, July 2327, 2001, Medford, Oregon, USA, pp 85-97.

Pozdnyakov L.K., 1952. Tree-like form of Siberian dwarfpine. Botanicheskij Journal 37(5): 688-691 (In Russian).

Samils B., Lagercrantz U., Lascoux M., Gullberg U., 2001. Genetic structure of Melampsora epitea populations in Swedish Salix viminalis plantations. European Journal of Plant Pathology. 107: 399-409. DOI: 10.1023/ A:1011270315251.

Stebbins G.L., 1959. The role of hybridization in evolu- 
tion. Proceedings of the American Philosophical Society. 103: 231-251.

Vasilyeva G.V., 2011. Seed production and seed progenygrowth of natural hybrids between Siberian stone pine (Pinus sibirica Du Tour) and Siberian dwarf pine ( $P$. pumila (Pall.) Regel). Ph.D. thesis. Tomsk. 24 p. (In
Russian).

Vos P., Hogers R., Bleeker M., Reijans M., Van de Lee T., Hornes M., Frijters A., Pot J., Peleman J., Kuiper M., Zabeau M., 1995. AFLP: a new technique for DNA fi ngerprinting. Nucleic Acids Research. 23: 4407-4414. DOI: $10.1093 /$ nar/23.21.4407. 